\title{
Continuous detoxification of carcinogenic aromatic amines by activated sludge treatment
}

\author{
Samir I. Gadow', Habib Md. Ahsan² and Yu-You Li ${ }^{3}$
}

\author{
${ }^{1}$ Department of Agricultural Microbiology, Agriculture and Biology Research Division, National \\ Research Centre, 33 EI Buhouth St., Dokki, Cairo 12622, Egypt. \\ ${ }^{2}$ Department of Chemistry, Graduate School of Science, Tohoku University, 6-3 Aza-aoba, Aramaki, \\ Sendai 980-8578, Japan \\ ${ }^{3}$ Department of Civil and Environmental Engineering, Graduate School of Engineering, Tohoku \\ University, 6-6-06 Aza-Aoba, Aramaki, Aoba-ku, Sendai, Miyagi 980-8579, Japan
}

Received: 10 May 2019/ Accepted 20 July 2019/ Publication date: 30 July 2019

\begin{abstract}
During anaerobic treatment of azo dyes containing wastewater, carcinogenic aromatic amines are often produced. Therefore, a plexiglass lab-scale continuous bio-reactor was built for anaerobic effluent of azo dye degradation contained aromatic amines. The system was operated at $35 \pm 1^{\circ} \mathrm{C}$ temperature and $\mathrm{pH}$ was maintained between 7.6- 7.9 for over 4 months with an effective volume of 5 liters and hydraulic retention time (HRT) of 72, 48 and $24 \mathrm{~h}$. The results of electrospray ionization (ESI) analysis showed that the main by-products of methanogenesis of C.I. acid red 88 were 2naphthylamine (2NA) and 4-Amino-1-naphthalene sulfonic acid. Our results suggested that the 2NA cannot be used as the sole carbon and energy source because of its toxicity at substrate level concentrations and the ratio of MLVSS/MLSS was decreased from 0.7 to 0.3 with $3 \%$ of COD removal. On the other hand, during the recovery period, approximately 20 days acclimation with glucose $\left(400 \mathrm{mg}^{-1}\right)$ as co-substrate was required to obtain an enrichment culture able to degrade 2NA and other aromatic amines. The maximum 2NA mineralization reached $75.4 \%$ removal at HRT of $24 \mathrm{~h}$ and the system is expected to have a better economic performance under HRT of $24 \mathrm{~h}$.
\end{abstract}

Keywords: Land cover; Land cover change; Land degradation; Remote Sensing; GIS; Egypt.

\section{Introduction}

The anaerobic treatment of azo dyes had high performances of chemical oxygen demand (COD) and color removal with great interest in bioenergy recovery and energy-saving options (Najme et al., 2015). However, many aromatic amines such as 2-naphthylamine were generated as by-products (Wang et al., 2019; Yang et al., 2018; Yaseen \& Scholz, 2019) which have been shown to induce cancer at specific physiologic sites in laboratory animals, thus resulting in their indirect implication as human carcinogens by example. In fact, most of these compounds eventually find their way into the water as a result of industrial discharge therefore, the fate of the aromatic amines in the environment needs to explore. Different innovations have been accounted for $2 \mathrm{NA}$ removal which incorporates different adsorbents such as zeolitic imidazolate (Wang et al., 2019) and multiwall carbon nanotubes/iron oxides/cyclodextrin composite (Hu et al., 2011). However, these techniques are facing several economic and technical limitations. On the other hand, biological treatment is getting more attention as an environmentally friendly option and cost-efficient concept. 2-naphthylamine (2NA or 1-amino-naphthalene) is an intermediate by-product of azo dyes biodegradation under anaerobic conditions and manufacture (Popli \& Patel, 2015). Also, many other chemicals of herbicides and a rubber antioxidant also contained 2NA in its manufacturing (Chen et al., 2006; Dikusar \& Kozlov, 2006; Oliveros et al., 1997; Zhu et al., 2000). In the literature, biodegradation of 2NA has been rarely reported previously and there was conflicting data regarding its fate in activated sludge. These aromatic amines could be accumulated in the bio-system and able to kill the microorganisms and/or change the microbial community structure in wastewater treatment plants (WWTP), which could lead to the threat of the drinking water safety. Therefore, the scientific communities need to explore innovative, cost-effective, energy-saving and sustainable solutions to reduce the risks to acceptable levels in the treated discharge. Consequently, this study aimed to optimize aerobic treatment of

Corresponding Author: Samir I. Gadow, Department of Agricultural Microbiology, Agriculture and Biology Research Division, National Research Centre, 33 EI Buhouth St., Dokki, Cairo 12622, Egypt. E-mail: ami0gw@hotmail.com 
recalcitrant cariogenic aromatic amines using activated sludge treatment under different hydraulic retention time (HRT). Additionally, the study also aims to evaluate the continuous long-term operation of the degradation performance and stability.

\section{Materials and Methods}

\section{Reactor setup and operation}

A Plexiglas lab-scale reactor was configured for UASB effluent as a post-treatment (see fig 1). The reactor was directly fed in continuous mode with the output of the UASB reactor. The system was operated at $35 \pm 1{ }^{\circ} \mathrm{C}$ temperature and $\mathrm{pH}$ was between 7.6- 7.9 for over 4 months with an effective volume of 5 liters and hydraulic retention time (HRT) of 72, 48 and $24 \mathrm{~h}$. The reactor was filled with activated sludge from the wastewater treatment plant in Miyagi, Japan. The air was provided by a constant-speed pump (APN-085, Iwaki, Japan) to the bottom of the reactor, to mix and supply the oxygen. The $\mathrm{DO}$ concentration in the reaction zone and the $\mathrm{pH}$ in the sedimentation zone was regularly measured using a portable DO meter (HORIBA OM-70, Japan) and $\mathrm{pH}$ meter (HORIBA D72 , Japan). While the $\mathrm{pH}$ was not controlled, it remained at a constant $7.6 \pm 0.2$ throughout the entire operation.

\section{Electrospray ionization (ESI) analysis}

The liquid sample from the bioreactor was filtrated using a $0.22 \mu \mathrm{m}$ filter and then evaporated using a rotary evaporator under vacuum at $35^{\circ} \mathrm{C}$ which was the same temperature of reactor operation condition until the dryness. The dry residual was analyzed by Electrospray ionization. Mass spectra were acquired on a Waters Xevo G2 Q-TOF spectrometer equipped with electrospray ionization (ESI) probe, with positive reflector mode acquisition.

\section{Analytical methods}

The volatile suspended solids (VSS), volatile solids (VS), Mixed liquor suspended solids (MLSS), Mixed liquor volatile suspended solids (MLVSS), protein and chemical oxygen demand (COD) were measured according to the procedures described in the Standard Methods (APHA, 2005).

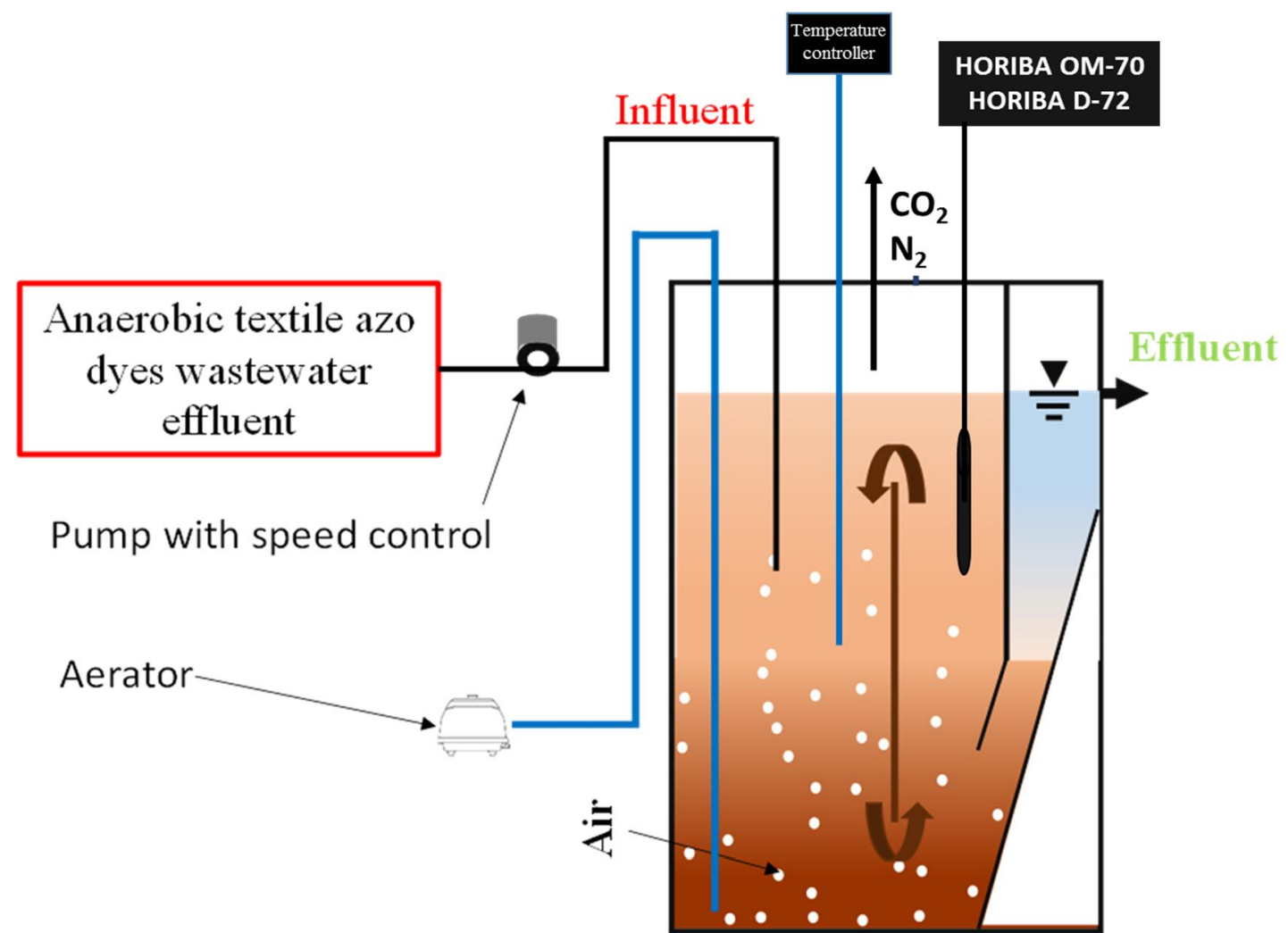

Fig. 1: Systematic diagram of experimental design. 


\section{Results and Discussion}

\section{Effect of continuous aerobic bio-reactor on anaerobic textile effluent treatment}

A lab-scale of the bioreactor was configured for continuous treatment of UASB effluent as a post-treatment. Three different organic loading rates were designated to investigate the effect of the bio-system on treatment performance and stabilization. Figure 2 shows that the bio-system performance under continuous mode for 120 days. Although, anaerobic treatment of azo dyes had high performances of chemical oxygen demand (COD) removal with values ranged between 80 and $92 \%$ based on operation conditions (Yu et al., 2012). As well as, the process had capable of color removal. However, the absorption peak of anaerobic effluent appeared in wavelength ranges about $195 \mathrm{~nm}$ to $246 \mathrm{~nm}$ that identified to aromatic amines regions (Tan et al., 2000). The results of electrospray ionization (ESI) analysis showed that the main by-product of methanogenesis of C.I. acid red 88 was 2-naphthylamine and 4-Amino-1-naphthalene sulfonic acid; our results suggested that the 2-naphthylamine cannot be used as the sole carbon and energy source because of its toxicity at substrate level concentrations and the ratio of MLVSS/MLSS was decreased from 0.7 to 0.3 (see figure 3 (4)).

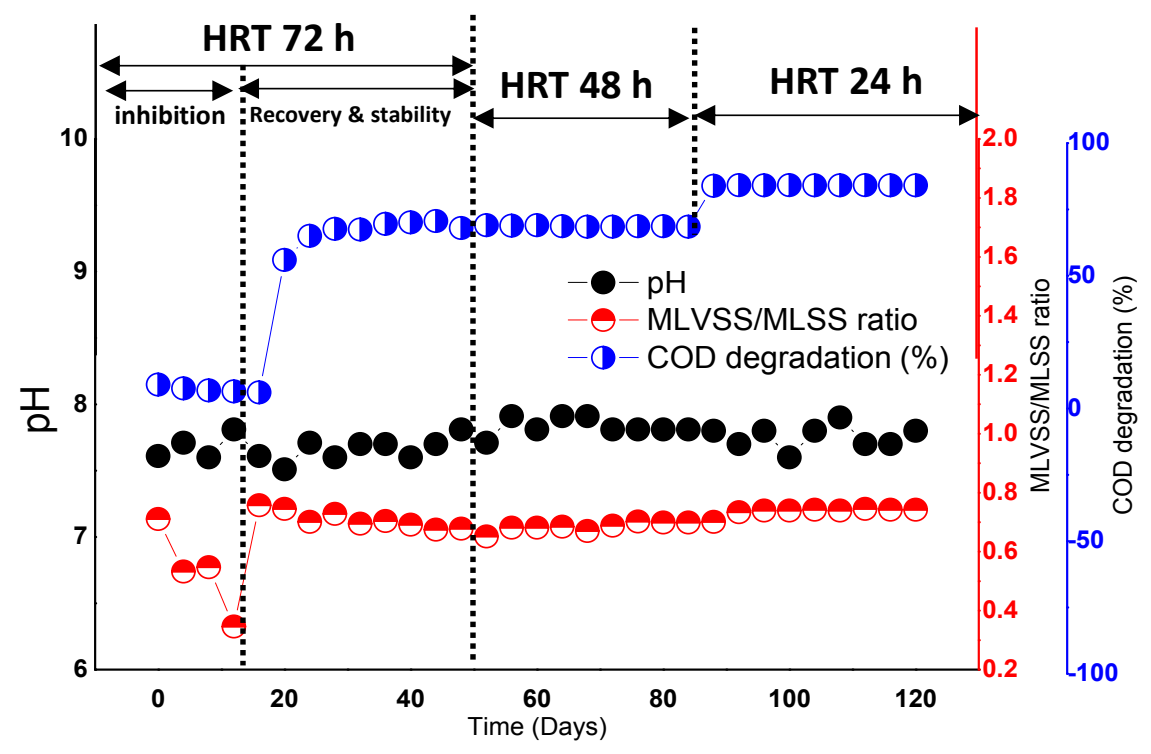

Fig. 2: The bio-reactor performance and stability.

Additionally, the COD degradation was decreased up to $3 \%$ which means the biodegradation of 2NA by activated sludge was uncertain (see figure 3 (3) \& figure 4). Previous investigates discussed the logical approach is to use an integrated anaerobic-aerobic process for removing color and organics. However, the effect of aromatic amines in influent on the MLVSS/MLSS ratio of activated sludge has not been reported within the scope of the relevant literature. In the previous study, over $50 \%$ inhibition was occurred at $15 \mathrm{mg} \mathrm{l}^{-1}$ of $2 \mathrm{NA}$ in the nitrification process using Nitrobacter and Nitrosomonas species isolated from activated sludge (Hockenbury \& Grady Jr, 1977). Furthermore, it was reported that the 2NA was inhibitory to oxygen uptake of activated sludge (Baird et al., 1977) and the percentage of membrane-damaged cells was increased as N-Phenyl-2-naphthylamine exposure concentration increased (Cheng et al., 2017).

\section{Electrospray ionization (ESI) data and analysis}

The ESI-mass data confirmed the formation of the 2-naphthylamine and 4-Amino-1naphthalene sulfonic acid. Figure 5 showed that the ESI-mass spectrum of the 1-napthylamine shows a peak at $\mathrm{m} / \mathrm{z}=144.9655$ (2-naphthylamine $+\mathrm{H}^{+}$) (calculated $\left.\mathrm{m} / \mathrm{z}=144.9655\right)$ is correspond to 2naphthylamine. The peak at $\mathrm{m} / \mathrm{z}=222.0246$ (calculated $\mathrm{m} / \mathrm{z}=222.0246$ ) is correspond to 4-Amino-1naphthalene sulfonic acid. These results confirmed that the main by-product of anaerobic biodegradation was 2-naphthylamine with more than $50 \%$ of the total intensity. Thus, it could be 
concluded that the metabolism of C.I. Acid Red88 in mesophilic anaerobic condition could be expressed as the following reaction:-

$$
\mathrm{C}_{25} \mathrm{H}_{42} \mathrm{~N}_{7} \mathrm{O}_{18} \mathrm{P}_{3} \mathrm{~S} \quad \frac{37^{\circ} \mathrm{C}}{\text { Anaerobic treatment }} \quad \mathrm{C}_{10} \mathrm{H}_{9} \mathrm{~N}+\mathrm{C}_{10} \mathrm{H}_{9} \mathrm{NO}_{3} \mathrm{~S}
$$

In the previous studies, the medical investigation of the carcinogenesis mode of the 2naphthylamine has been confirmed to the dogs with daily doses of $400 \mathrm{mg}$ (Purchase et al., 1981) and urinary bladder carcinogens (Hein et al., 1993; Srivastava et al., 2019). Additionally, the other byproduct causes skin, eyes and respiratory irritation (PubChem, 2008).
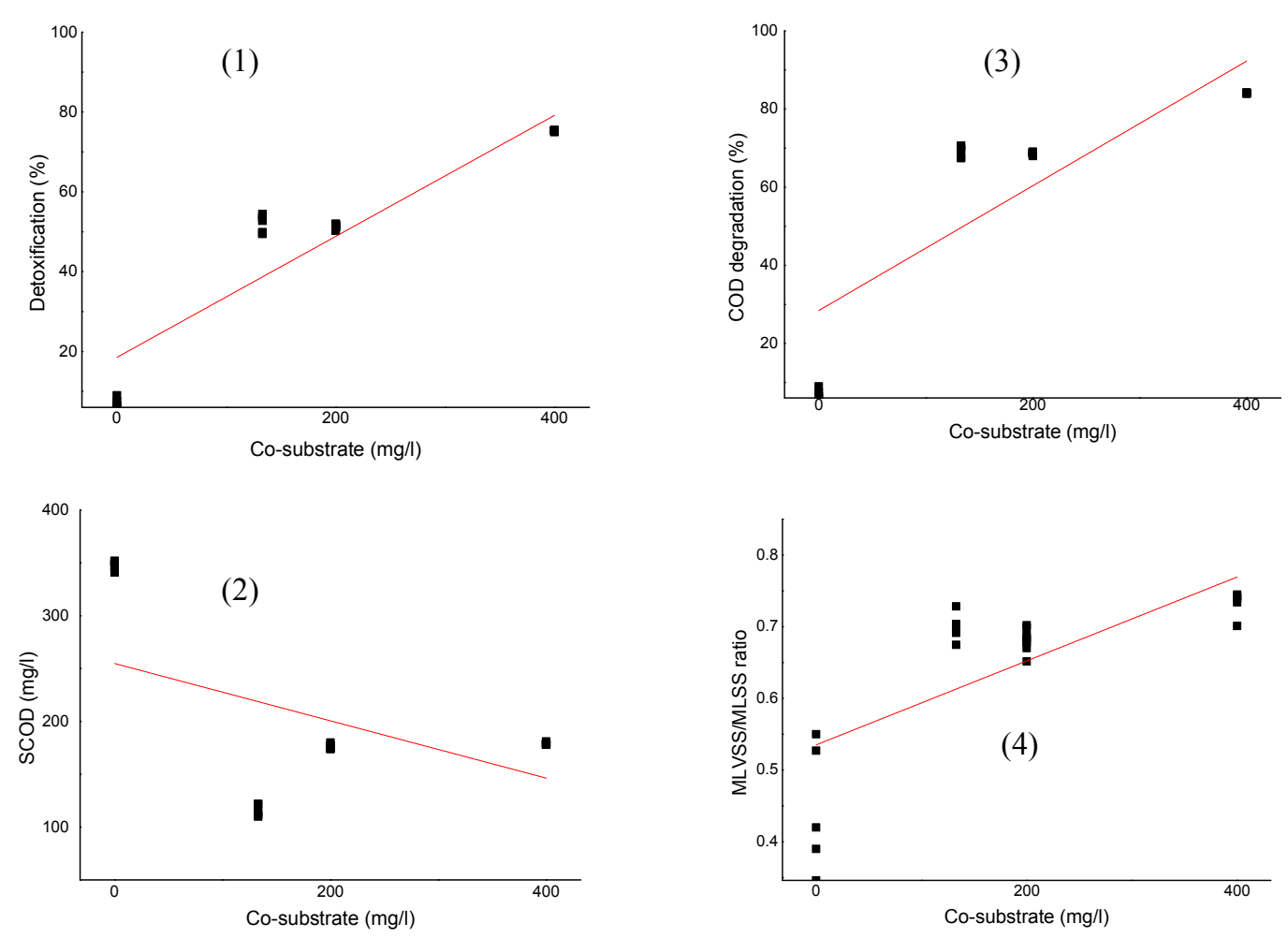

Fig. 3: Linear fit of detoxification, SCOD, degradation and MLVSS/MLSS ratio

\section{Effect of co-substrate on the bio-reactor performance and degradation efficiency}

The 5 litter bioreactor was continuously maintained on $72 \mathrm{~h}$ HRT with $400 \mathrm{mg} \mathrm{l}^{-1}$ glucose after the deterioration period for 32 days operation. The experimental results showed that the bioreactor was successfully treated and removed the COD and the MLVSS/MLSS ratio was improved during the recovery and steady-state periods (see figure 4). The COD degradation reached 65 and $71 \%$ under recovery and steady-state periods, respectively (see figure 5 (3). In the same line, the MLVSS/MLSS ratio was increased from 0.32 to 0.7 as well as the protein concentration was also increased from 0.12 to $0.17 \mathrm{mg} \mathrm{l}^{-1}$ as a result of adding $400 \mathrm{mg}$ glucose as a co-substrate (see figure 5). At the recovery period, the average rate of biodegradation of $2 \mathrm{NA}$ reached $54 \%$ removal. The results confirmed that the co-metabolism is a key factor for detoxification and removal of aromatic amines in activated sludge treatment. The previous study agreed with no biodegradation of 2NA as the sole of carbon source after 20 days inoculation in activated sludge (Pitter, 1976) however, acclimation with salicylic acid as the primary source of carbon were required to obtain an enrichment culture able to degrade 2NA (Babcock et al., 1993). Our results confirmed that the co-substrate has played unique roles in solving the problem and sustainability. 


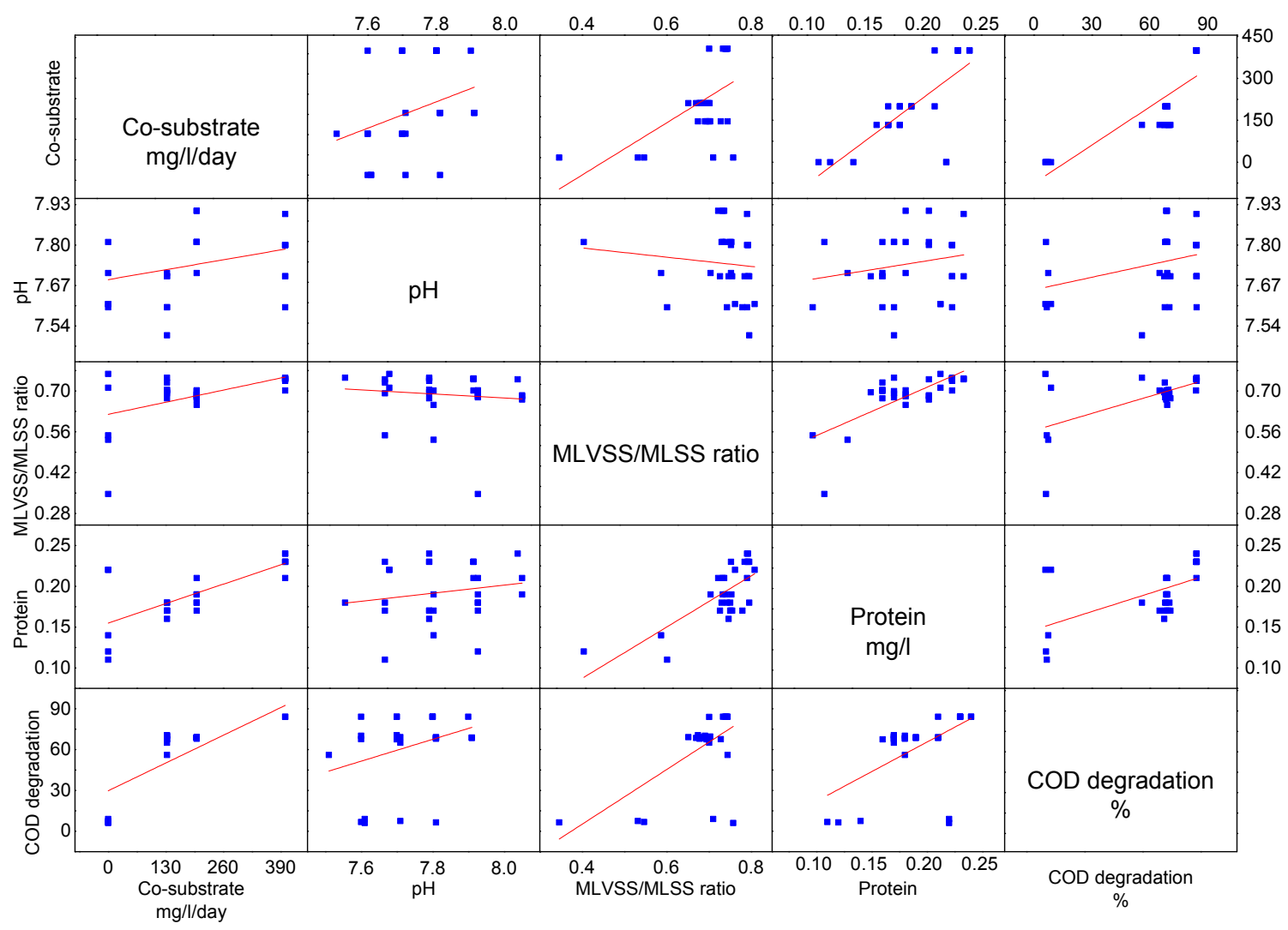

Fig. 4: The scatter matrix of the whole data on the bio-reactor performance

\section{Effect of $\mathbf{H}$}

\section{$R T$ on the bio-reactor performance}

Three different HRTs were selected to investigate the effect of OLR on 2NA biodegradation and bioreactor long-term stability (Table 1). At HRT of $72 \mathrm{~h}$, the steady-state was started after 12 days operation with maximum COD mineralization of $71 \%$ and the $\mathrm{pH}$ was maintained at 7.7. By increasing HRT, the bioreactor showed better performance to COD biodegradability and treatment stability.

Table 1: Bio-reactor performance at different HRT

\begin{tabular}{ccccc}
\hline $\begin{array}{c}\text { HRT } \\
(\mathrm{h})\end{array}$ & $\begin{array}{c}\text { OLR } \\
\left(\mathbf{m g ~ C O D ~ L ~}^{-1} \mathbf{d}^{-\mathbf{1}}\right)\end{array}$ & $\mathbf{p H}$ & $\begin{array}{c}\text { MLVSS/MLSS } \\
\text { ratio }\end{array}$ & $\begin{array}{c}\text { COD degradation } \\
\mathbf{( \% )}\end{array}$ \\
\hline $\begin{array}{c}72 \text { (without co- } \\
\text { substrate) }\end{array}$ & 241.4 & $7.7 \pm 0.17$ & $0.42 \pm 0.11$ & 3.3 \\
72 & 374.7 & $7.7 \pm 0.11$ & $0.70 \pm 0.04$ & 69.1 \\
48 & 562.1 & $7.8 \pm 0.12$ & $0.68 \pm 0.03$ & 68.7 \\
24 & 1124.2 & $7.8 \pm 0.10$ & $0.70 \pm 0.04$ & 84.1 \\
\hline
\end{tabular}

The maximum COD degradation was obtained at HRT of $24 \mathrm{~h}$ with $84.1 \%$ removal (see figure 6). Therefore, these results suggested that the increase of co-substrate concentration could be increased the 2NA biodegradation due to improving the microbial biodiversity and co-metabolism and the glucose is a relatively economical carbon source with which to grow large numbers of microorganisms. The results confirmed that the microorganisms in aerobic granular sludge showed the ability to degrade high-strength organics in shorter HRT, compared to suspended culture (Show et al., 2010). Moreover, the biological effect of HRT was clear in protein concentration in the active zone. Figure 6 showed that the concentrations of total protein were increased by increasing HRT with the maximum percentage of $35 \%$ at HRT of $24 \mathrm{~h}$ compared to $72 \mathrm{~h} \mathrm{HRT}$. 


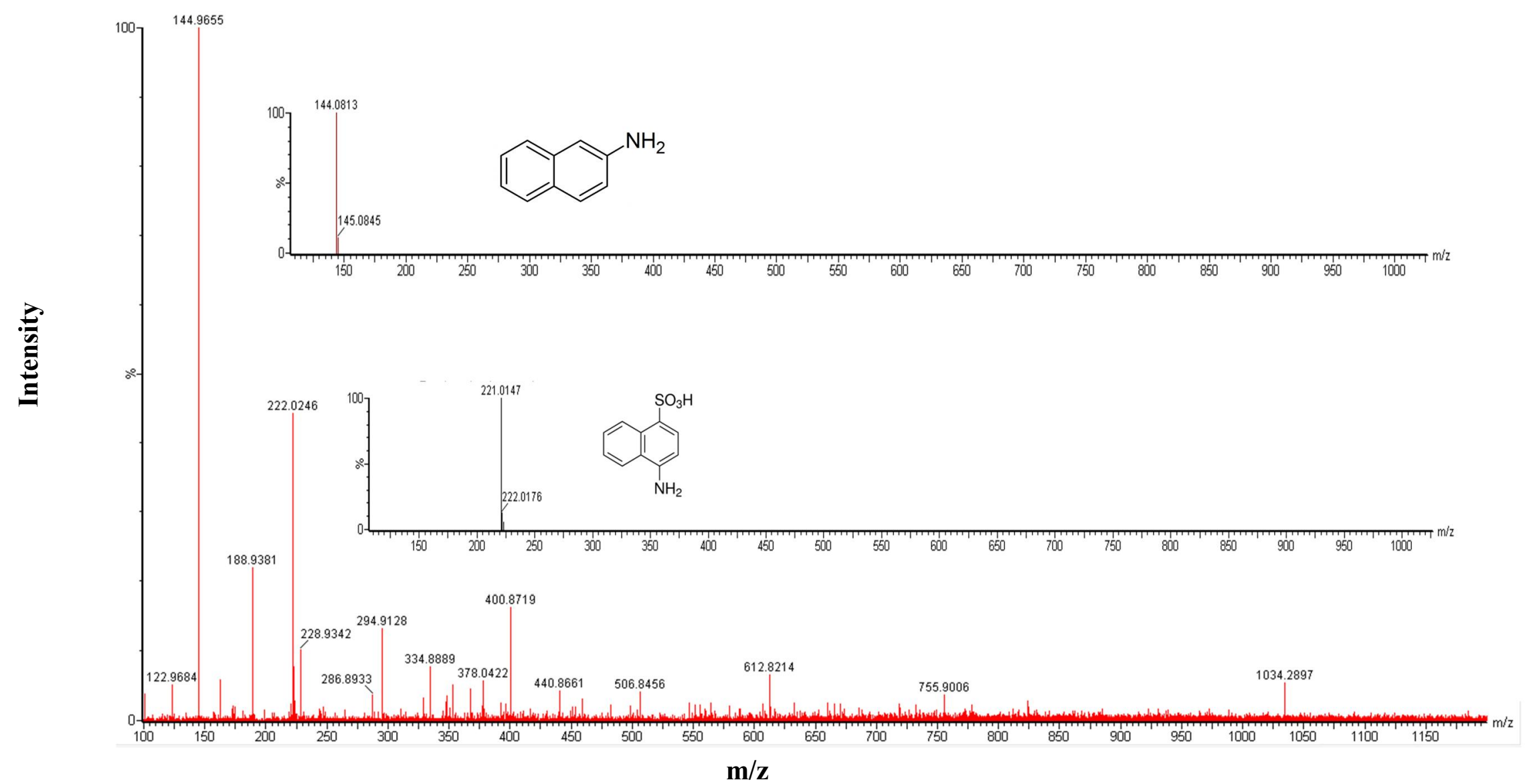

Fig. 5: Gas chromatography mass spectrometry analysis of anaerobic effluent of azo dye. 


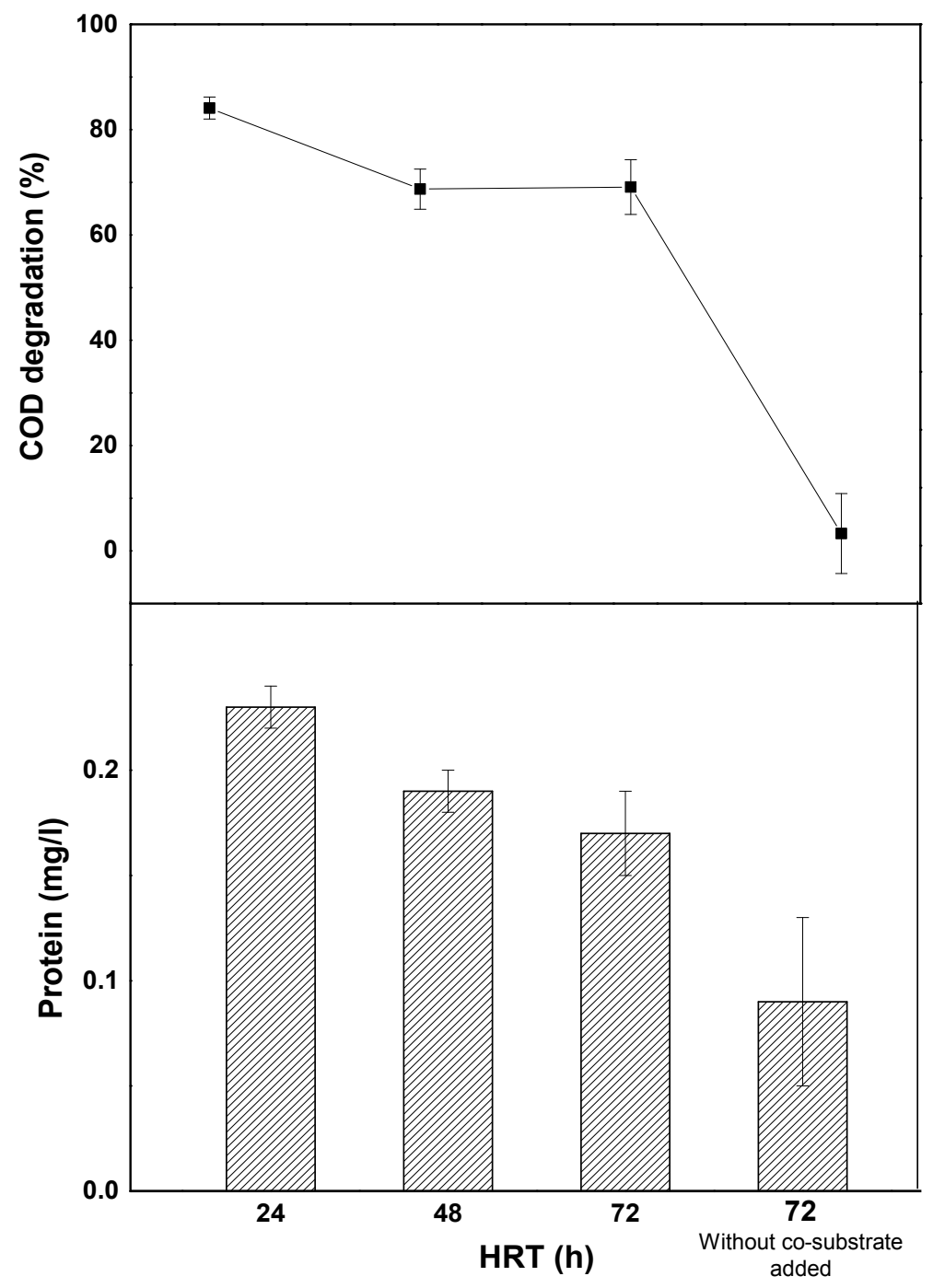

Fig. 6: Effect of HRT on COD degradation and protein concentration.

\section{The COD mass balance and detoxification}

Recently, many studies reported that the efficient technologies to remove the aromatic amine in particular 2NA were different adsorbents, such as zeolitic imidazolate (Wang et al., 2019), carbon nanomaterials (Wang et al., 2007), metal-organic frameworks (MOFs) (Bai et al., 2015; Li et al., 2018), and layered double hydroxide (LDH) (Zhu et al., 2017), etc. However, these techniques are still facing several economic and technical limitations. Our system, biological treatment, showed efficient detoxification and COD removal of organic pollution (see figure 3 (1\&2)). At steady-state conditions, the 2NA was effectively mineralized at different OLR. The maximum 2NA mineralization reached $75.4 \%$ removal at HRT of $24 \mathrm{~h}$ (see figure $6 \& 7$ ). The COD mineralization reached 69.1, 68.7 and $84 \%$ at HRT of 72,48 and $24 \mathrm{~h}$, respectively. The Normal probability plot shows clearly that the all data are close to their reference lines, indicating that the normal percentiles and detoxification follow a normal distribution (see figure 7). Consequently, our results suggested that the present biosystem has better economic performance and large scale application. 


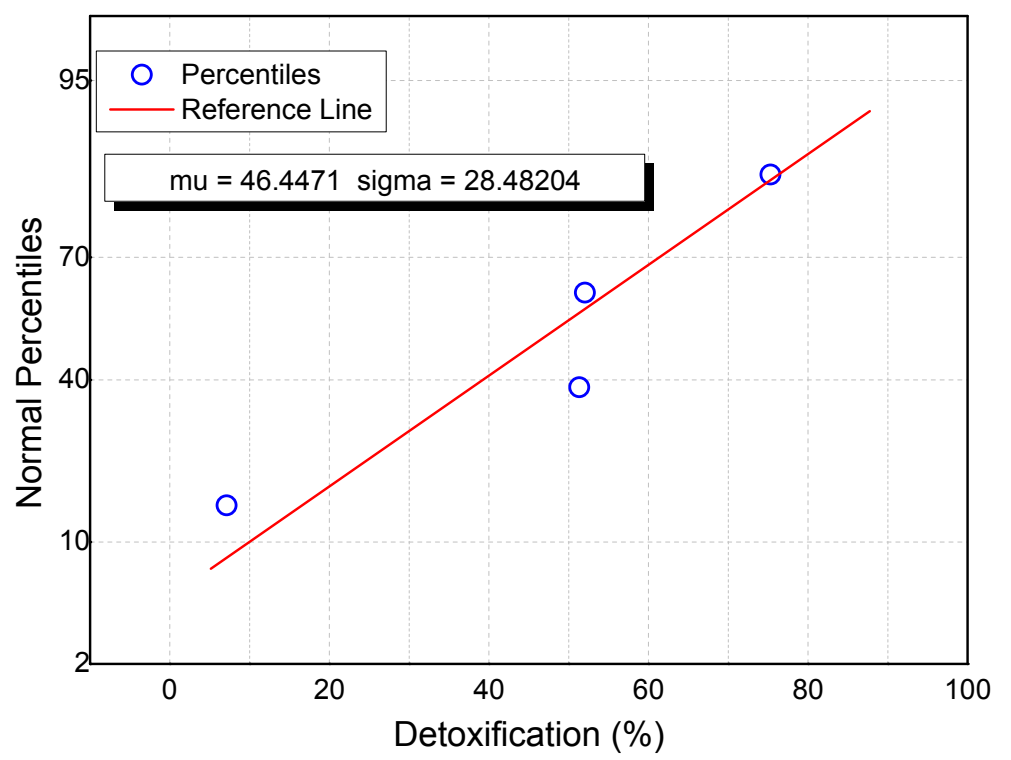

Fig. 7: Normal Probability Plot of detoxification

\section{Conclusion}

A continuous aerobic bio-reactor was operated to treat the 2NA as intermediate of azo dyes degradation under anaerobic conditions. The reactor was maintained at $35 \pm 1{ }^{\circ} \mathrm{C}$ temperature and $\mathrm{pH}$ was between 7.6- 7.9 for over 4 months with an effective volume of 5 liters and hydraulic retention time (HRT) of 72, 48 and $24 \mathrm{~h}$. The results of Electrospray ionization (ESI) analysis showed that the main by-product of methanogenesis of C.I. acid red 88 was 2-naphthylamine; our results suggested that the 2-naphthylamine cannot be used as the sole carbon and energy source because of its toxicity at substrate level concentrations. However, as a result of adding co-substrate, the experimental results showed that the bioreactor was successfully treated and removed the COD and the MLVSS/MLSS ratio was improved during the recovery and steady-state periods. The maximum $2 \mathrm{NA}$ mineralization reached $75.4 \%$ removal at HRT of $24 \mathrm{~h}$ and the system is expected to have a better economic performance under HRT $24 \mathrm{~h}$.

\section{References}

APHA, 2005. Standard methods for the examination of water wastewater, 21, 258-259.

Babcock, R.W., W. Chen, K.S. Ro, R.A. Mah and M.K. Stenstrom, 1993. Enrichment and kinetics of biodegradation of 1-Naphthylamine in activated sludge. Applied Microbiology Biotechnology, 39(2): 264-269.

Bai, Z.Q., L.Y. Yuan, L. Zhu, Z.R. Liu, S.Q. Chu, L.R. Zheng, J. Zhang, Z.F. Chai and W.Q. Shi, 2015. Introduction of amino groups into acid-resistant MOFs for enhanced U (VI) sorption. Journal of Materials Chemistry A, 3(2), 525-534.

Baird, R., Carmona, L., Jenkins, R.L. 1977. Behavior of benzidine and other aromatic amines in aerobic wastewater treatment. Journal (Water Pollution Control Federation) 1609-1615.

Chen, T., E. Kang, G. Tan, S. Liu, S. Zheng, K.Yang, S.Tong, C. Fang, F. Xiao and Y.Yan, 2006. Highly selective catalytic prep aration of bis (4-oxo-benzo-2-cyclohexen-1-yl) amine from 1naphthylamine oxidation over metalloporphyrin catalysts by molecular oxygen under air pressure and by hydrogen peroxide. Journal of Molecular Catalysis A: Chemical, 252(1-2), 56-62.

Cheng, L., Y. He, Y. Tian, B. Liu, Y. Zhang, Q. Zhou and Z.Wu, 2017. Comparative biotoxicity of N-Phenyl-1-naphthylamine and N-Phenyl-2-naphthylamine on cyanobacteria Microcystis aeruginosa. Chemosphere, 176, 183-191.

Dikusar, E. and N. Kozlov, 2006. Synthesis of Schiff bases from 1-naphthylamine and vanillin, vanillal, and their O-acyl derivatives. Russian Journal of Organic Chemistry, 42(3): 369-375.

Hein, D.W., M.A. Doll, T.D. Rustan, K. Gray, Y. Feng, R.J. F erguson and D.M. Grant, 1993. Metabolic activation and deactivation of arylamine carcinogens by recombinant human NAT1 and polymorphic NAT2 acetyltransferases. Carcinogenesis, 14(8), 1633-1638. 
Hockenbury, M.R. and C.L. Grady Jr, 1977. Inhibition of nitrification--effects of selected organic compounds. Journal (Water Pollution Control Federation), 768-777.

Hu, J., D. Shao, C. Chen, G. Sheng, X. Ren and X. Wang, 2011. Removal of 1-naphthylamine from aqueous solution by multiwall carbon nanotubes/iron oxides/cyclodextrin composite. Journal of Hazardous Materials, 185(1): 463-471.

Li, J., X. Li, A. Alsaedi, T. Hayat and C. Chen, 2018. Synthesis of highly porous inorganic adsorbents derived from metal-organic frameworks and their application in efficient elimination of mercury (II). Journal of colloid interface science, 517, 61-71.

Najme, R., S. Hussain, Z. Maqbool, M. Imran, F. Mahmood, H. Manzoor, T. Yasmeen and T. Shahzad, 2015. Biodecolorization of Reactive Yellow-2 by Serratia sp. RN34 isolated from textile wastewater. Water Environment Research, 87(12), 2065-2075.

Oliveros, E., O. Legrini, M. Hohl, T. Miiller and A. Braun, 1997. Large scale development of a lightenhanced Fenton reaction by optimal experimental design. Water Science Technology, 35(4), 223-230.

Pitter, P., 1976. Determination of biological degradability of organic substances. Water research, 10(3), 231-235.

Popli, S. and U.D. Patel, 2015. Destruction of azo dyes by anaerobic-aerobic sequential biological treatment: a review. International Journal of Environmental Science and Technology 12(1): 405420.

PubChem. 2008. https://pubchem.ncbi.nlm.nih.gov/compound/sodium_4-aminonaphthalene-1sulfonate hydrate.

Purchase, I., A. Kalinowski, J. Ishmael, J. Wilson, C. Gore and I. Chart, 1981. Lifetime carcinogenicity study of 1-and 2-naphthylamine in dogs. British Journal of Cancer, 44(6), 892.

Show, K.Y., Tay, J.H., Hung, Y.-T. 2010. Global perspective of anaerobic treatment of industrial wastewater. in: Environmental Bioengineering, Springer, pp. 773-807.

Srivastava, A., K.A. Gautam and S. Sankhwar, 2019. Molecular Biomarkers and Urinary Bladder Cancer (UBC). in: Molecular Diagnostics in Cancer Patients, Springer, pp. 219-235.

Tan, N., A. Borger, P. Slenders, A. Svitelskaya, G. Lettinga and J. Field, 2000. Degradation of azo dye Mordant Yellow 10 in a sequential anaerobic and bioaugmented aerobic bioreactor. Water Science Technology, 42(5-6), 337-344.

Wang, H., A. Zhou, F. Peng, H. Yu and J. Yang, 2007. Mechanism study on adsorption of acidified multiwalled carbon nanotubes to $\mathrm{Pb}$ (II). Journal of Colloid Interface Science, 316(2), 277-283.

Wang, J., Y. Li, Z. Lv, Y. Xie, J. Shu, A. Alsaedi, T. Hayat and C. Chen, 2019. Exploration of the adsorption performance and mechanism of zeolitic imidazolate framework-8@ graphene oxide for $\mathrm{Pb}$ (II) and 1-naphthylamine from aqueous solution. Journal of Colloid İnterface Science, $542,410-420$.

Yang, B., H. Xu, J. Wang, D. Yan, Q. Zhong and H. Yu, 2018. Performance evaluation of anaerobic baffled reactor (ABR) for treating alkali-decrement wastewater of polyester fabrics at incremental organic loading rates. Water Science Technology, 77(10): 2445-2453.

Yaseen, D., Scholz, M. 2019. Textile dye wastewater characteristics and constituents of synthetic effluents: a critical review. International Journal of Environmental Science Technology, 16(2): 1193-1226.

Yu, L., W.W. Li, M.H.W. Lam, H.Q. Yu and C. Wu, 2012. Isolation and characterization of a Klebsiella oxytoca strain for simultaneous azo-dye anaerobic reduction and bio-hydrogen production. Applied Microbiology Biotechnology, 95(1): 255-262.

Zhu, K., S. Lu, Y. Gao, R. Zhang, X. Tan and C. Chen, 2017. Fabrication of hierarchical core-shell polydopamine@MgAl-LDHs composites for the efficient enrichment of radionuclides. Applied Surface Science, 396, 1726-1735.

Zhu, L., B. Chen and X. Shen, 2000. Sorption of phenol, p-nitrophenol, and aniline to dual-cation organobentonites from water. Environmental Science Technology, 34(3), 468-475. 